\title{
Behavior of RC Beams Strengthened with NSM- CFRP Strips Subjected to Fire Exposure
}

\author{
A Numerical Study
}

\author{
Hayder A. Al-Baghdadi \\ Department of Civil Engineering \\ College of Engineering \\ University of Baghdad \\ Baghdad, Iraq \\ baghdadi.hayder@coeng.uobaghdad.edu.iq
}

\author{
Anwer Sabah \\ Department of Civil Engineering \\ College of Engineering \\ University of Baghdad \\ Baghdad, Iraq \\ anwer.ali1801m@coeng.uobaghdad.edu.iq
}

\begin{abstract}
The use of Near-Surface Mounted (NSM) CarbonFiber-Reinforced Polymer (CFRP) strips is an efficient technology for increasing flexural and shear strength or for repairing damaged Reinforced Concrete (RC) members. This strengthening method is a promising technology. However, the thin layer of concrete covering the NSM-CFRP strips is not adequate to resist heat effect when directly exposed to a fire or at a high temperature. There is clear evidence that the strength and stiffness of CFRPs severely deteriorate at high temperatures. Therefore, in terms of fire resistance, the NSM technique has a significant defect. Thus, it is very important to develop a set of efficient fire protection systems to overcome these disadvantages. This paper presents a numerical study that investigates the fire behavior of thermally insulated RC beams flexurally strengthened with NSM-CFRP strips and subjected to fire exposure according to the ISO 834 standard. The numerical study considered three-dimensional finite element models in the ABAQUS software that have been developed to simulate and predict the performance (thermal and structural response) of fire endurance tests on strengthened, uninsulated strengthened, and thermally insulated beams strengthened with NSM-CFRP strips, which were exposed to fire and had different fire insulation schemes. The insulation used was plaster from local material with a thickness range of 25 to $50 \mathrm{~mm}$. The variation of the thermal and mechanical properties with the temperature of the constituent materials was considered. All beams' mechanical and thermal responses were adequately simulated using numerical models. The results of the numerical simulations were in good agreement with the experimental data. The fire behavior of the NSM-CFRP strengthened RC beams was examined and particularly the efficiency of the NSM strengthening system during the fire. The behavior in the fire of the NSM-CFRP strengthening system on the RC beams thermally protected with different fire insulation schemes was assessed. Finally, the effectiveness of fire insulation was studied.
\end{abstract}

Keywords-Near-Surface Mounted (NSM); Carbon Fiber Reinforced Polymer (CFRP); RC beams; fire exposure

\section{INTRODUCTION}

Strengthening technologies based on Fiber-ReinforcedPolymer (FRP) composites have recently emerged as a possible alternative to infrastructure issues. FRP materials are appealing to civil engineers because of their resistance to electrochemical corrosion, their high ratio of strength to weight, and their fabrication pliability. FRP is a modern type of building material made up of resin-saturated fibers (polymeric matrix). FRPs have high tensile strength, low thermal conductivity, corrosion resistance, residual stress strength, availability in a variety of configurations, lower maintenance costs, ease of installation, and mechanical fixing. Since the '90s the FRPs have seen widespread use in civil constructions [1].

FRP materials are highly susceptible to the consequences of high temperatures. At a temperature close to the polymer adhesive matrix's glass transition temperature $\left(T_{g}\right)$ substantial mechanical and/or bonding degradation can be predicted. This raises the possibility of a sudden and disastrous collapse during a burn. Furthermore, the majority of organic polymer matrix products are flammable. Also flame spread, smoke production, and toxicity must be considered [2]. Near-Surface Mounted (NDSM) FRP reinforcement is used in a growing number of applications. This system is based on the concept of embedding FRP reinforcements (e.g. bars or laminates) into grooves created by slotting the concrete members' surface with an adhesive (organic or inorganic) in the concrete cover of the elements to be strengthened. Externally Bonded FRP Reinforcement (EBR FRP) has several advantages over the NSM system: (a) It is possible to reduce the needed amount of site installation work. (b) NSM bars can be easily anchored into adjacent members to prevent debonding failures. (c) NSM reinforcement can be pre-stressed more easily. This feature is particularly appealing in the flexural strength. The FRP reinforcement in NSM is slitted instead of being externally bonded. This provides additional fire safety opportunities. (g) The NSM system has better bonding properties and protects the FRP bars or strips from accidental impact, mechanical damage, fire, and vandalism, due to the concrete cover. The polymer binder in these composites does not have the same fire resistance as the fibers used in FRPs. As a result, fires damage concrete buildings reinforced with FRPs. In reality, when compared to the EBR, the NSM technique provides better effectiveness and anchoring capacity because the strengthening material is within the concrete cover [3-9]. 


\section{DESCRIPTION OF THE FINITE ELEMENT MODELS}

\section{A. Geometry and Element Types}

The studied three-dimensional (3D) Finite Element (FE) models simply support RC beams flexturally strengthened with NSM-CFRP strips. An NSM-CFRP strip strengthened RC beam was modeled as a reference. The geometry, dimensions, and configuration of the beams were identical to the tested specimens. The insulated modeled RC beam is $1850 \mathrm{~mm}$ in length and has a rectangular cross-section of $225 \mathrm{~mm}$ and $130 \mathrm{~mm}$ in depth and width respectively, and a concrete cover of $20 \mathrm{~mm}$. Two $8 \mathrm{~mm}$ diameter steel rebars were used to model the top and bottom internal steel reinforcement. The transverse stirrups were identical, made from steel with $8 \mathrm{~mm}$ diameter and the distance between stirrups kept constant at $60 \mathrm{~mm}$. The beam was strengthened with two CFRP strips that have a crosssection of $15 \mathrm{~mm}$ (width) $\times 1.2 \mathrm{~mm}$ (thickness) and a total length of $1450 \mathrm{~mm}$ was applied on the beams' grooves according to the NSM technique. The adhesive layer was modeled as a fully bonded model. Plaster with a thickness ranging from $25 \mathrm{~mm}$ to $50 \mathrm{~mm}$ was used to insulate the three sides and ends of the RC beam as shown in Figure 1. It should be noted that an anchorage length of approximately $550 \mathrm{~mm}$ was determined [10]. Two concentrated static loads, spaced $550 \mathrm{~mm}$ apart, were applied to the beam, giving it a shear span of $500 \mathrm{~mm}$.

The FE models included unburned and burned beams. The unburned beam comprised of 4 parts. These parts were concrete, longitudinal and stirrup steel reinforcements, the steel rods of loading and the supports, and the CFRP strips. Concrete, steel rods of loading, and supports, were modeled with the C3D8R 3D 8-node linear brick solid element with reduced integration $(\mathrm{R})$, whereas steel reinforcement bar and stirrup elements were modeled using the 3-D 2-node truss element T3D2. The CFRP was modeled using the 3D 4-node shell element termed S4R.
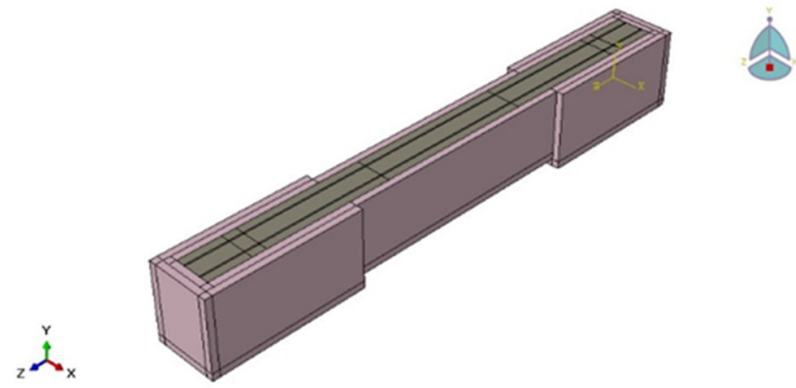

Fig. 1. Assemby of the whole insulated and strengthening RC beam parts, FEM analysis.

For the burned uninsulated beam, concrete was modeled using the 3D 8-node linear heat transfer brick solid element titled DC3D8, while the heat transfer 2-node DC1D2 was the selected link element as the steel reinforcement. The CFRP was modeled using the heat transfer quadrilateral DS4 3D 4-node shell element. For the burned insulated beams, an additional part was modeled: the linear3D 8-node hexahedral heat transfer brick DC3D8 element was selected as the insulation element. The overall brick element mesh is shown in Figure 2.

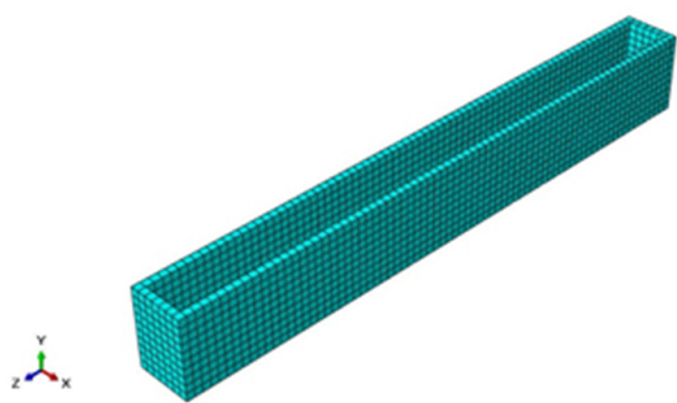

Fig. 2. Meshing for brick elements, FEM analysis.

\section{B. Material Properties at Ambient Temperature}

Concrete was modeled as an elastic and isotropic material. ABAQUS requires the identification of 2 parameters: modulus of elasticity and Poisson's ratio. Equation (1) in [11] was used to determine the modulus of elasticity of concrete. A value between 0.15 and 0.2 was used for the Poisson's ratio for concrete based on [12]. Moreover, to simulate the inelastic behavior of concrete, the Concrete Damage Plasticity Model (CDPM) is used. Five parameters are required for CDPM to be defined: the dilation angle $(\psi)$, the flow potential eccentricity (e), the ratio of initial equibiaxial compressive yield stress to the initial uniaxial compressive yield stress $\left(f_{b 0} / f_{c 0}\right)$, the parameter $(K)$ which is used to define the multi-axial behavior of concrete, and the viscosity $(\mu)$.

$$
E_{c}=4700 \sqrt{f_{c}^{\prime}}
$$

Table I lists the CDPM parameters adopted in this study. The data for the compressive and tensile behavior of concrete come from the uniaxial compression and uniaxial tension tests in [12].

TABLE I. CDPM PARAMETERS ADOPTED IN THIS STUDY

\begin{tabular}{|c|c|c|c|c|c|}
\hline $\begin{array}{c}\text { Specimen } \\
\text { description }\end{array}$ & \multicolumn{5}{|c|}{ Reinforced concrete beams strengthened with CFRP } \\
\hline Parameters & $\psi$ & $\boldsymbol{e}$ & $\boldsymbol{f}_{\boldsymbol{b} \mathbf{0}} / \boldsymbol{f}_{\boldsymbol{c} \mathbf{0}}$ & $\boldsymbol{K}$ & $\boldsymbol{\mu}$ \\
\hline Values & 40 & 0.1 & 1.16 & 0.667 & $1 \mathrm{e}-4$ \\
\hline $\begin{array}{c}\text { Specimen } \\
\text { description }\end{array}$ & \multicolumn{2}{|c|}{ Reinforced concrete beams strengthened with CFRP } \\
\hline Parameters & $\psi$ & $\boldsymbol{e}$ & $\boldsymbol{f}_{\boldsymbol{b} \mathbf{0}} / \boldsymbol{f}_{\boldsymbol{c} \mathbf{0}}$ & $\boldsymbol{K}$ & $\boldsymbol{\mu}$ \\
\hline Values & 50 & 0.1 & 1.16 & 0.667 & $1 \mathrm{e}-4$ \\
\hline
\end{tabular}

The steel reinforcement and stirrups were modeled using an elastic-perfectly plastic material, with modulus of elasticity and Poisson's ratio of $200000 \mathrm{MPa}$ and 0.3 respectively, which defined the linear isotropic part, while yield stress and plastic strain determine the bilinear isotropic part. Steel bearing rods and support rods were modeled as isotropic linear materials. The linear isotropic part is specified by the steel rods' modulus of elasticity and the Poisson's ratio, which are $200000 \mathrm{MPa}$ and 0.3 for each rod. As facilitation, the CFRP strips were modeled as a linear elastic isotropic brittle material. The Poisson's ratio of 0.3 was assigned to CFRP components at an ambient temperature [13], $\sigma_{p u}$ was $2800 \mathrm{MPa}$, the modulus of elasticity $E_{C F R P}$ was $160 \mathrm{GPa}$ according to the manufacturer's specifications of Sika ${ }^{\circledR}$ CarboDur ${ }^{\mathbb{P}}$ plates. The adhesive was also treated as a linear elastic isotropic brittle material [14]. A plaster made from local materials was used as the fire 
insulation system, with a thickness ranging from 25 to $50 \mathrm{~mm}$. It was applied on the three surfaces of the beam. The fire insulation system presents variable thickness along the beam's length, being typically thicker at the anchorage zones of the CFRP strips. The thermal conductivity and the specific heat capacity of the plaster at room temperature are $\lambda=0.15 \mathrm{~W} /(\mathrm{m} . \mathrm{K})$, and $C_{p}=1000 \mathrm{~J} /(\mathrm{kg} . \mathrm{K})$ respectively [15].

\section{Temperature-Dependent Material Properties}

Due to the considerable effect of temperature on the structural and thermal response of the CFRP-strengthened RC beams subjected to fire, the dependency of all material properties on temperature was taken into account in the models. The variation of concrete specific heat capacity, density, and thermal conductivity with temperature was provided in [15]. The concrete's density is taken to have a constant value of $2400 \mathrm{~kg} / \mathrm{m}^{3}$, and a constant emissivity value of 0.7 was considered. Classical concrete was adopted in simulations. The mechanical properties of concrete at room temperature were: average cylinders' compressive strength: $f_{c}^{\prime}=21 \mathrm{MPa}$, maximum tensile strength: $f_{t c}^{\prime}=1.512 \mathrm{MPa}$, and average modulus of elasticity: $E_{c}=21538 \mathrm{MPa}$. It was assumed that the reduction of these properties with temperature would follow the relationships indicated in [16]. The reduction with temperature of reinforcement steel mechanical properties suggested in [15] was included in the present models. The steel's density was taken as $7800 \mathrm{~kg} / \mathrm{m}^{3}$. The variation of the thermal properties of CFRP strips with temperature was determined by the data provided by [17]. According to [18], a constant with temperature CFRP emissivity of 0.7 was assumed. The CFRP bonding adhesive was modeled as a fully bonded model. The variation of the plaster properties with temperature was considered as reported in [16]. The variation of the plaster density and specific heat with temperature was determined according to [16] and a constant with temperature emissivity value of 0.7 was considered. The mechanical contribution of the fire protection schemes is expected to be negligible, consequently, it was not considered.

\section{THERMAL AND STRUCTURAL BOUNDARY CONDITIONS}

\section{A. Temperature-Dependent Material Properties}

\section{1) Thermal Boundaries}

To closely match the environments occurring during fire, the bottom face and the two lateral faces of the beams' models were directly exposed to fire according to the heating rate of ISO 834 standard fire curve. Figure 3 shows the thermal applied loads on the models, which represent the furnace temperature measured at the fire test, whereas the top face was submitted to the temperature of the air above the top face of the beam. The lateral faces were thermally insulated during the tests. The boundary conditions correspond to the thermal exposure of beams (adopted in the tests). Radiation and convection heat transfer modes were considered on top, bottom, and the two lateral faces, a convection coefficient $\left(h_{c}\right)$ of $25 \mathrm{~W} / \mathrm{m}^{2 \circ} \mathrm{C}$ (constant with temperature) was adopted, as suggested in [16]. The initial temperatures of the models were defined according to the recorded data of the beams test ranging between 10 and $20^{\circ} \mathrm{C}$.

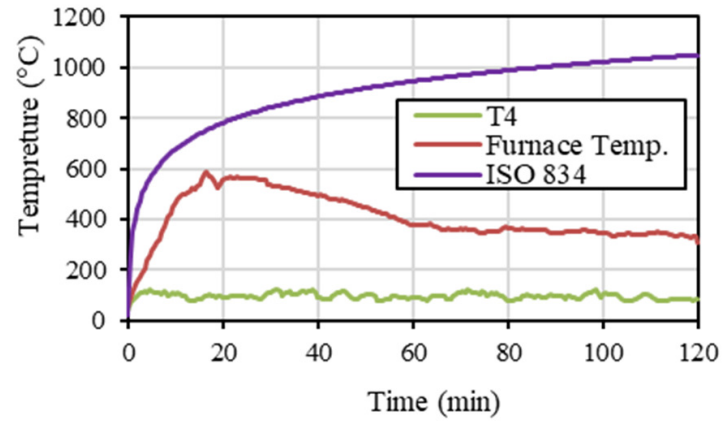

Fig. 3. Thermal applied loads on BSHP-25 and BSHP-50 beams' models.

\section{2) Structural Boundaries}

The beams were subjected to a mechanical load applied in a 4-point bending configuration. Simply supported boundary conditions were assigned to the beam-ends. These supports were simulated by elastic supports. One support provided restraint to both vertical and longitudinal displacements (directions $\mathrm{y}$ and $\mathrm{z}$ ), while it permitted rotations around the (xaxis), (pinned support). The second support provided restraint to only vertical displacements, (direction y) while still enabling longitudinal displacements and rotations about the x-plane axis, (roller support). These supports were initially applied on concrete beams subjected to concentrated load. An identical simplification was adopted for the applied load, each rod has equal to $(1 / 2)$ of the actual applied load (P). For all beams, the same increment of the experimentally applied load was adopted. It is worth pointing out that the beams' self-weight was not considered.

\section{RESULTS AND DISCUSSION}

Several comparisons between the numerical and the experimental findings are presented. These comprise the effect of elevated temperature, load-deflection relation under the applied load of the references, and post-fire reinforced beams. The temperature of the NSM-CFRP strengthened RC beams subjected to fire exposure was recorded at the opposite anchorage zone (thermocouples T1 and T2) and the mid-span section (thermocouple T3).

\section{A. Thermal Response (Temperature vs Duration of Fire Exposure)}

The comparison of the predicted (numerical) and recorded (experimental) temperatures as a function of the duration of fire exposure at various places are shown in Figures 4-6. For the uninsulated beam, it was noted that the FE model underestimated the temperatures along the central zone of the bonded interface. The differences are most likely due to the high difficulty of simulating the behavior of NSM-CFRPstrengthened RC members in fire (because of the thermal gradient that exists along the depth of the slits causing nonuniform thermal deterioration throughout its depth) and because the effect of concrete spalling on heat transfer indepth, which was not considered by the models. For the insulated beams, it was also found that the numerical model underestimated the temperatures along the center zone of the bonded interface. These variations are most likely the result of 
modeling without taking into account the impacts of plaster cracks and fall-off (which were seen in the experimental fire test) in simulations due to their high complexity. Falling off is an outcome of the formation of diverse discrete cracks in the gypsum. Gypsum fall-off in fire strongly influences the fire resistance of the insulated beams. However, modeling this phenomenon is exceedingly complex, and no scientific effort has yet been published that uses numerical methods to solve this problem [15].

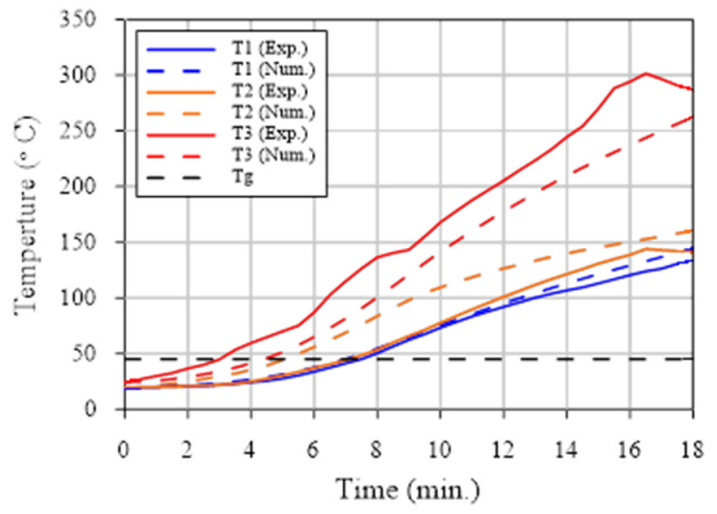

Fig. 4. Comparison of temperatures recorded at various locations of the BSH beam.

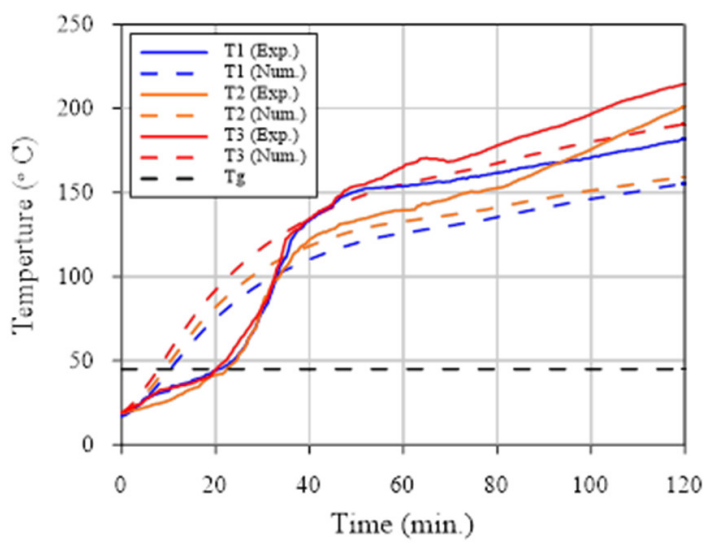

Fig. 5. Comparison of temperatures recorded at various locations of the BSHP-25 beam.

In comparison to their experimental counterparts, the predicted time-temperature curves show a more uniform temperature rise. The predicted temperature curves did not show any plateau (such as those recorded on the timetemperature curves in actual tests). This means that the influence of moisture content was not entirely captured by the thermal characteristics. There are some differences between the measured and the predicted temperatures. This might have occurred because the actual thermal characteristics of concrete and plaster utilized in the beams at increased temperatures differ from those included in the FE models. Despite the abovementioned deviations, generally all models gave a satisfying accuracy of the temperature development in the respective beams, demonstrating the FE models' capacity to correctly predict the thermal behavior of uninsulated and insulated NSM-CFRP beams exposed to fire. The comparison of the time the epoxy adhesive required to reach $\mathrm{T}_{\mathrm{g}}$ is listed in Table II and shown in Figures 7 and 8.

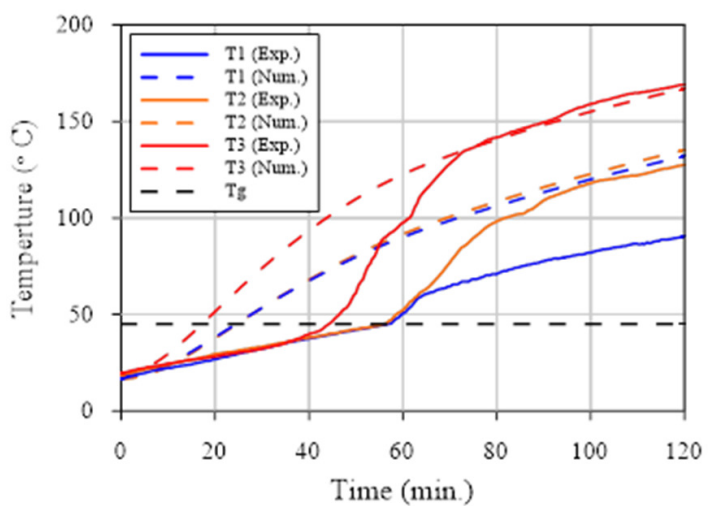

Fig. 6. Comparison of temperatures recorded at various locations of the BSHP-50 beam.

TABLE II. REQUIRED TIME COMPARISON FOR EPOXY ADHESIVE TO REACH $T_{g}$

\begin{tabular}{|c|c|c|c|c|}
\hline \multirow{2}{*}{ Beam code } & \multicolumn{3}{|c|}{ Time required to reach $\mathbf{T}_{\mathrm{g}}$ of epoxy adhesive (min.) } \\
\cline { 2 - 5 } & \multicolumn{2}{|c|}{ Central zone } & \multicolumn{2}{c|}{ Anchorage zones } \\
\cline { 2 - 5 } & Exp. & Num. & Exp. & Num. \\
\hline BSH & 3 & 6 & 7 & 7 \\
\hline BSHP-25 & 20 & 13 & 21 & 14 \\
\hline BSHP-50 & 44 & 26 & 56 & 35 \\
\hline
\end{tabular}

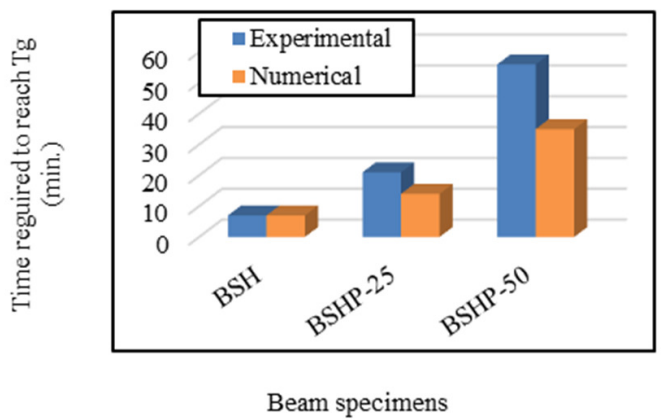

Fig. 7. Comparison of the time required to reach $T_{g}$ of epoxy adhesive at the central zone.

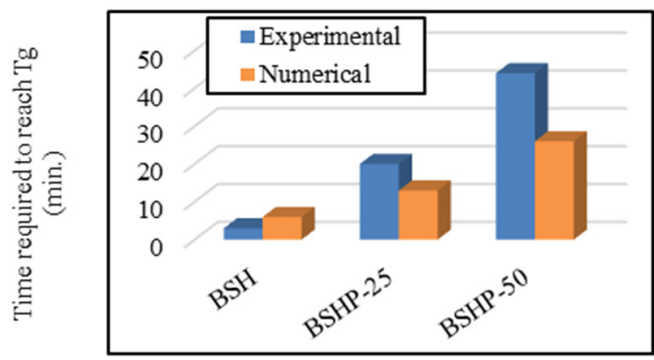

Beam specimens

Fig. 8. Comparison of the time required to reach $T_{g}$ of epoxy adhesive at the anchorage zones. 


\section{B. Structural Response (Load vs Mid-Span Displacement)}

Figures 9-12 show the measured and predicted mid-span displacement increments of all beams. From the FE analysis result, it can be seen that the models are stiffer than the experimental specimens. Some influences may be the cause for higher stiffness in FE analysis results. Micro-cracks resulting from the drying shrinkage and curing are found in the concrete during the experiment and after burning and cooling. These would decrease the actual specimens' stiffness. Modeling of these micro-cracks hasn't been conducted in FE models. Also, the bond between concrete and steel reinforcing or CFRP in the FE analysis is assumed perfect. This assumption is not totally true for real specimens. When bond-slip happens, composite work is lost between concrete and steel reinforcing. Therefore, the overall stiffness of the real specimens can be lower than the one expected from FE analysis.

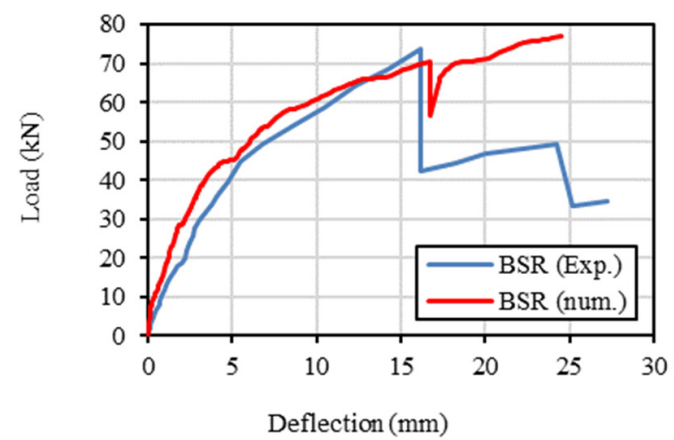

Fig. 9. Comparison of load vs deflection curves for BSR beam.

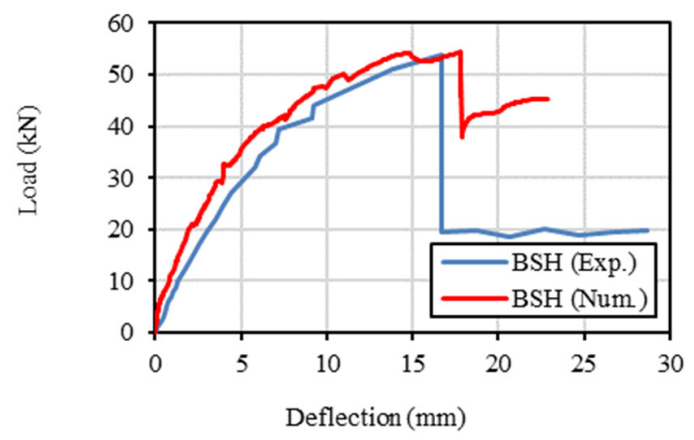

Fig. 10. Comparison of load vs deflection curves for BSH beam.

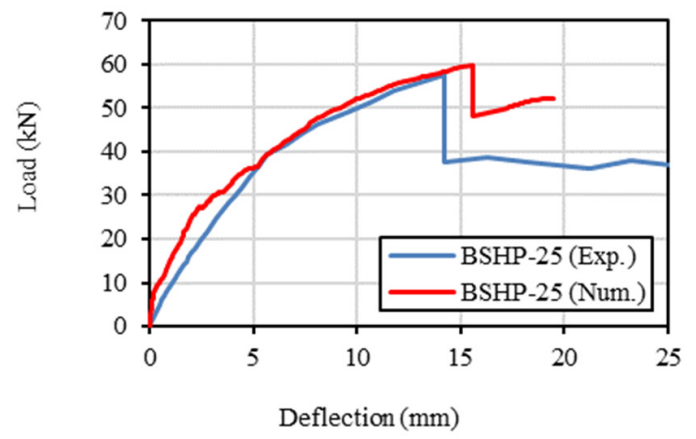

Fig. 11. Comparison of load vs deflection curves for BSHP-25 beam.

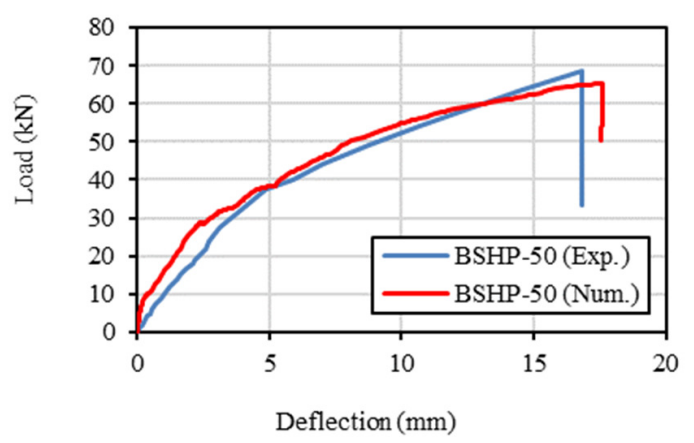

Fig. 12. Comparison of load vs deflection curves for BSHP-50 beam.

There are differences between the real temperature effects on materials' mechanical properties and those included in the models. All beams' mechanical responses were adequately simulated using numerical models. In terms of load versus deflection curves, strength, and stiffness, the results of numerical simulations were in good agreement with the experimental data. Table III lists the ultimate load and deflection, as found in FE analysis and the experimental work for all specimens under static test. All failure loads obtained from FE analysis (except BSR and BSHP-50) show an overestimation of the real experimental values.

TABLE III. COMPARISON BETWEEN THE NUMERICAL AND EXPERIMENTAL ULTIMATE LOAD AND DEFLECTION OF THE TESTED SPECIMENS

\begin{tabular}{|c|c|c|c|c|}
\hline \multirow{2}{*}{$\begin{array}{c}\text { Beam } \\
\text { code }\end{array}$} & \multicolumn{2}{|c|}{ Ultimate load(kN) } & \multicolumn{2}{c|}{ Ultimate deflection (kN) } \\
\cline { 2 - 5 } & Exp. & Num. & Exp. & Num. \\
\hline BSR & 73.72 & 70.46 & 16.21 & 16.75 \\
\hline BSH & 53.71 & 54.37 & 16.68 & 17.79 \\
\hline BSHP-25 & 57.73 & 59.85 & 14.25 & 15.59 \\
\hline BSHP-50 & 68.82 & 65.16 & 16.81 & 17.32 \\
\hline
\end{tabular}

\section{CONCLUSION}

The conclusions from the findings of the current study can be summarized as:

- The numerical models were able to estimate the thermal behavior of the insulated $\mathrm{RC}$ beams that strengthened NSM-CFRP that were exposed to fire adequately. In addition, the flextural responses of the FE models for all beams were in good agreement with the experimental findings.

- The structural performance of reference beams, uninsulated and insulated NSM CFRP-strengthened RC beams subjected to static load after being exposed to fire according to the standard fire curve was adequately predicted.

- From the FE analysis result, it can be seen that the models are stiffer than the experimental specimens.

- The numerical results indicate that using thicker insulation in the CFRP anchoring zones (applied using NSM methods) reduced the required time the adhesive temperature needs to reach glass transmission temperature $T_{g}$. 
- The predicted time-temperature curves show a uniform temperature rise, while the predicted temperature curves did not show any plateau (such as those recorded on the timetemperature curves in actual tests). This shows that the influence of moisture content is not entirely captured by the thermal characteristics.

- The numerical models underestimated the temperatures along the center zone of the bonded interface. These variations are most likely the result of modeling without taking into account the impacts of plaster cracks and fall-off (which were seen in the experimental fire test) in simulations due to their higher complexity.

\section{ACKNOWLEDGMENTS}

The authors would like to express their gratitude to the staff of the Civil Engineering Department of the University of Baghdad for their scientific and professional help. The authors would also like to thank the staff of the Civil Engineering Department's Structural Laboratory of the University of Baghdad for their support.

\section{REFERENCES}

[1] N. T. K. Al-Saadi, A. Mohammed, R. Al-Mahaidi, and J. Sanjayan, "A state-of-the-art review: Near-surface mounted FRP composites for reinforced concrete structures," Construction and Building Materials, vol. 209, pp. 748-769, Jun. 2019, https://doi.org/10.1016/j.conbuildmat. 2019.03.121.

[2] V. K. R. Kodur, L. A. Bisby, and M. F. Green, "Preliminary Guidance for the Design of FRP-strengthened Concrete Members Exposed to Fire," Journal of Fire Protection Engineering, vol. 17, no. 1, pp. 5-26, Feb. 2007, https://doi.org/10.1177/1042391507061956.

[3] R. El-Hach, S. Rizkalla, and R. Kotynia, "Modelling of Reinforced Concrete Flexural Members Strengthened with Near-Surface Mounted FRP Reinforcement," in 7th Int. Symp. on Fiber Reinforced Polymer (FRP) Reinforcement for Concrete Structures, Jan. 2005, pp. 16811700 .

[4] J. A. O. Barros, S. J. E. Dias, and J. L. T. Lima, "Efficacy of CFRPbased techniques for the flexural and shear strengthening of concrete beams," Cement and Concrete Composites, vol. 29, no. 3, pp. 203-217, Mar. 2007, https://doi.org/10.1016/j.cemconcomp.2006.09.001.

[5] R. Seracino, N. M. Jones, M. S. Ali, M. W. Page, and D. J. Oehlers, "Bond Strength of Near-Surface Mounted FRP Strip-to-Concrete Joints," Journal of Composites for Construction, vol. 11, no. 4, pp. 401-409, Aug. 2007, https://doi.org/10.1061/(ASCE)1090-0268(2007)11: 4(401).

[6] L. De Lorenzis and J. G. Teng, "Near-surface mounted FRP reinforcement: An emerging technique for strengthening structures," Composites Part B: Engineering, vol. 38, no. 2, pp. 119-143, Mar. 2007, https://doi.org/10.1016/j.compositesb.2006.08.003.

[7] M. a. J. Hassan and A. F. Izzet, "Experimental and Numerical Comparison of Reinforced Concrete Gable Roof Beams with Openings of Different Configurations," Engineering, Technology \& Applied Science Research, vol. 9, no. 6, pp. 5066-5073, Dec. 2019, https://doi.org/10.48084/etasr.3188.

[8] H. M. Hekmet and A. F. Izzet, "Numerical Analysis of Segmental Post Tensioned Concrete Beams Exposed to High Fire Temperature," Engineering, Technology \& Applied Science Research, vol. 9, no. 5, pp. 4759-4768, Oct. 2019, https://doi.org/10.48084/etasr.3059.

[9] A. H. Buller, M. Oad, B. A. Memon, and S. Sohu, "24-hour Fire Produced Effect on Reinforced Recycled Aggregates Concrete Beams," Engineering, Technology \& Applied Science Research, vol. 9, no. 3, pp. 4213-4217, Jun. 2019, https://doi.org/10.48084/etasr.2764.
[10] ACI-Committee-440.2R-17, ACI PRC-440.2-17: Guide for the Design and Construction of Externally Bonded FRP Systems for Strengthening Concrete Structures. West Conshohocken, PA, USA: ACI, 2017.

[11] ACI-Committee-318-19, ACI 318-19: Building Code Requirements for Structural Concrete. West Conshohocken, PA, USA: ACI, 2019.

[12] Y. Dere, "Nonlinear FE Modeling of Reinforced Concrete," International Journal of Structural and Civil Engineering Research, vol. 6, no. 1, pp. 71-74, 2017, https://doi.org/10.18178/ijscer.6.1.71-74.

[13] J. P. Firmo and J. R. Correia, "Fire behaviour of thermally insulated RC beams strengthened with EBR-CFRP strips: Experimental study," Composite Structures, vol. 122, pp. 144-154, Apr. 2015, https://doi.org/10.1016/j.compstruct.2014.11.063.

[14] Z. S., "Behaviour, and modelling of RC beams strengthened in flexure with near-surface mounted FRP strips," Ph.D. dissertation, Hong Kong Polytechnic University, Hong Kong, China, 2012.

[15] I. Rahmanian, "Thermal and Mechanical Properties of Gypsum Boards and Their Influences on Fire Resistance of Gypsum Board Based Systems," Ph.D. dissertation, University of Manchester, Manchester, UK, 2011.

[16] UNE EN 1992-1-2:2011/A1:2021 Eurocode 2: Design of concrete structures - Part 1-2: General rules - Structural fire design. 1992.

[17] C. A. Griffis, R. A. Masumura, and C. I. Chang, "Thermal Response of Graphite Epoxy Composite Subjected to Rapid Heating," Journal of Composite Materials, vol. 15, no. 5, pp. 427-442, Sep. 1981, https://doi.org/10.1177/002199838101500503.

[18] J. R. Miller and P. M. Weaver, "Temperature profiles in composite plates subject to time-dependent complex boundary conditions," Composite Structures, vol. 59, no. 2, pp. 267-278, Feb. 2003, https://doi.org/10.1016/S0263-8223(02)00054-5. 